\title{
LA PROVIDENCIA DIVINA EN CERVANTES
}

Cervantes tiene un alto concepto de la Escritura, a la que llama "divina", "santa", "sacra" o "palabra del mismo Dios" (Prólogo I Parte). Cita expresamente títulos de libros bíblicos, como depósitos de la verdad: Libro de los Reyes (Prólogo I Parte); El Licenciado Vidriera cita dos veces el Libro del Eclesiástico y el Salmo 104, como obras del Espíritu Santo. El canónigo del Quijote cita el Libro de los Jueces $(\mathrm{I}, 49)$ y se dice que el juramento ha de hacerse sobre los cuatro santos Evangelios $(\mathrm{I}, 10)$, «lugar de la verdad" según La Gitanilla; en el Persiles se citan unas palabras del Libro del Levitico, dichas por el mismo Dios (I,XVIII).

Según mis datos, las alusiones a la Biblia sobrepasan las 300 , de las cuales 22 son citas literales en latín y 43 literales en castellano, procedentes de la Vulgata latina, en ediciones anteriores a la oficial Clementina (1592); unas 200 son alusiones o reminiscencias de palabras, hechos o instituciones de la Biblia; se nombran 30 personajes de la Escritura como modelos éticos o hazañas históricas protagonizadas por ellos; finalmente aparecen unos 30 refranes que tienen su origen en el texto sagrado, procedentes de los Libros Sapienciales, de modo ordinario.

Una de estas alusiones a la Biblia, son los textos que hacen referencia a la Providencia Divina: unos a favor de todos los seres de la creación (hombres, animales y plantas); otros suponen un castigo medicinal por el pecado, como "voluntad o permisión de Dios" para nuestra corrección y curación.

La primera manifestación de este atributo divino aparece en la primera parte del Quijote, en su capítulo 18, aunque ya había aludido a la Providencia en obras anteriores como La Galatea. 
Don Quijote se dirige a Sancho ante las preocupaciones de qué comer, pues le habian robado las alforjas donde llevaban los alimentos:

\footnotetext{
"Más con todo esto, sube en tu jumento, Sancho el Bueno, y vente tras mi; que Dios, que es proveedor de todas las cosas, no nos han de faltar, y más andando tan en su servicio como andamos, pues no falta a los mosquitos del aire, ni a los gusanillos de la tierra ni, a los renacuajos del agua; y es tan piadoso, que hace salir su sol sobre los buenos y los malos, y llueve sobre los injustos y justos" $(I, 18)$.
}

Estas preocupaciones de don Quijote y Sancho por la comida, que le habían robado, obedece al discurso de Cristo sobre la Providencia. El Evangelio propone dos ejemplos que abarcan los espacios visibles: Aves del cielo y lirios del campo:

«No andéis preocupados por vuestra vida, qué comeréis, ni por vuestro cuerpo, con qué os vestiréis... Mirad las aves del cielo: no siembran ni cosechan, ni recogen en graneros: y vuestro padre celestial las alimenta. ¿No valéis vosotros más que ellos?" (Mt. 6,25-26).

"Y del vestido ¿por qué preocuparos? Observad los lirios del campo cómo crecen: no se fatigan ni hilan. Pero yo os digo que ni Salomón, en toda su gloria, se vistió como uno de ellos" (Mt. 6,28-29).

La Biblia divide siempre todo el espacio visible en "cielo" y "tierra". Cervantes añade el "agua" como elemento distinto de ella: mosquitos del aire (cielo), gusanos de la tierra y renacuajos del agua. En la Adjunta al Parnaso se sujeta a dos: "sabandijas de la tierra y gusarapos del agua». Solamente en un texto se refiere a las aves del Evangelio: (II,33).

"Y las avecitas del campo tienen a Dios por proveedor y dispensero"

En los demás casos cambia las aves y los lirios por animales todavía más insignificantes: mosquitos, gusanos, renacuajos, sabandijas, gusarapos. En estas sustituciones aparece el artificio literario y culto de un Cervantes creador. Es un intento de vulgarizar más la enseñanza evangélica, apartándose de lo que siempre se podía oír en los sermones. Aquí no hay acomodaciones del texto a otras circunstancias, pues se trata del mismo contexto en ambos escritos.

La última frase del texto cervantino, que hace su presencia también en el refranero español, responde literalmente a un dicho de Jesús:

«...vuestro Padre celestial, que hace salir su sol sobre malos y buenos y llover sobre justos e injustos" (Mt. 5,45). 
El Fénix español es un hombre obsesionado por la Providencia. Quizás alude y confía en ella tanto por los numerosos peligros y necesidades de su azarosa vida: soldado contra los turcos, preso en varias cárceles y vida angustiosa en lo económico antes de cobrar fama y dineros por sus obras. Dios se preocupó de su vida, que fue a mejor. En muchos textos sobre la Providencia, que iremos desgranando, nos demuestra su sentido cristiano de la vida. En estos casos hablará con la «lengua del alma» (II,16), y como le dijo su escudero: "Más bueno era vuestra merced para predicador que para caballero andante» $(I, 18)$.

De nuevo adapta los datos evangélicos a otros animales: la hormiga:

"De las hormigas [aprender] la Providencia» (II, 12).

El texto es una parte del párrafo donde nuestro escritor diserta sobre lo que debemos aprender de los animales (cigüeñas, perros, hormigas), y al parecer es una cita de la Historia Natural de Plinio, según Clemencín, Rodríguez Marín, Riquer y otros. De todas maneras, el "exemplum» de la hormiga es tópico, pues también el Libro de los Proverbios lo aduce contra los perezosos que no trabajan ni proveen para el futuro:

"Vete donde la hormiga, perezoso,

mira sus andanzas y te harás sabio.

Ella no tiene jefe, ni capataz, ni amo;

asegura en el verano su sustento,

recoge su comida al tiempo de la mies" (Prov. 6,6-8).

La sabiduría de la hormiga es celebrada en el mismo libro junto a los damanes, las langostas y los lagartos (Prov. 30,25).

En la Adjunta al Parnaso, Cervantes adopta una postura crítica contra los malos poetas. Nuestro escritor recibe una carta de Apolo con diversas instrucciones para los vates españoles. De nuevo el dios pagano alude a la Providencia, en la que añade dos nuevos animales como "ejemplo»:

«Item se da aviso que si algún poeta fuere favorecido de algún príncipe, ni le visite a menudo, ni le pida nada, sino déjese llevar de la corriente de su ventura; que el que tiene providencia de sustentar las sabandijas de la tierra y los gusarapos del agua, la tendrá de alimentar a un poeta, por sabandija que sea."

Cervantes nunca mendigó favores de los poderosos o mecenas; de aquí su dura crítica contra los poetas aduladores que viven a expensas de los señores. Pero a pesar de ello, Dios los sustentará "por muy sabandija que sea", metáfora en sentido peyorativo de un animal repugnante. 
No sólo Dios dará de comer a los poetas, sino a todos los hombres:

"Que los cielos que sustentan los gusarapos del agua, tendrá cuidado de sustentar a los hombres de la tierra" (Persiles, II, XIV y III, XI).

Otros ejemplos de la Providencia son las hojas de los árboles y los cabellos de la cabeza, que no caen sin la voluntad de Dios. Así escribe Cervantes:

"Encomendadlo a Dios, Sancho -dijo don Quijote-; que todo se hará bien y quizás mejor de lo que vos pensáis; que no se mueve la hoja en el árbol sin la voluntad de Dios" (II,3).

También hay una correspondencia bíblica. La traducción de la Vulgata suena de este modo: "Toda carne envejece como el heno, y como la hoja que da frutos en el árbol verde: unas brotan y otras caen" (Ecclo. 14,18).

Sobre los cabellos escribe a propósito de la derrota de la Armada Invencible, como prevista y ordenada por Dios:

"Pues no se excusa lo que el cielo ordena,

ni puede en ningún tiempo los cabellos

tener algunos con la mano asidos.... (Canción II a la Armada Invencible).

La referencia bíblica se halla en el Evangelio:

«¿No se venden dos pajarillos por un as? Pues bien, ni uno de ellos caerá en tierra sin el consentimiento de vuestro Padre. En cuanto a vosotros, hasta los cabellos de vuestra cabeza están todos contados" (Mt. 10,29-30; Lc. 12,7 y 21,18 ).

No basta con afirmar la existencia y valor de la Providencia. Cervantes rechaza el concepto de "Fortuna", propia de los paganos y contraria a la Providencia evangélica:

"Lo que sé decir es que no hay fortuna en el mundo, ni las cosas que en él suceden, buenas o malas que sean, vienen acaso [por casualidad], sino por particular Providencia de los cielos, y de aquí lo que suele decirse: Cada uno es artífice de su ventura" $(\mathrm{II}, 66)$.

El Persiles insiste en la misma idea:

"Estas mudanzas tan extrañas caen debajo del poder de aquella que comúnmente es llamada Fortuna, que no es otra cosa sino un firme disponer del cielo.»

Que Dios dirige los destinos del mundo, y nada sucede por casualidad, es doctrina abundante en la Biblia (véanse los salmos 145 y 147 enteros; Ps. 54,23; Job. 38; I Pedr. 5,7, etc.). 
La apostilla de Cervantes: "cada uno es artífice de su ventura", da pie a Américo Castro para hacer una interpretación según el determinismo que le caracteriza. Para él la cita demuestra que los acontecimientos proceden de la naturaleza, llamada "mayordomo de Dios" en La Galatea (Lib. IV) y no de la Providencia divina: destino y Providencia se funden en un mismo destino '.

Amiano Peña, uno de sus comentadores, señala con acierto:

"Américo Castro parece desconocer el sentido escolástico de Providencia al confundirle con hado. Su laicismo le lleva a oponer la "natura naturans" a Dios, desconociendo la distinción escolástica de Dios "causa prima" y naturaleza "causa secunda", de creación, conservación y gobierno de la "natura naturata", o mundo creado. Todos sus errores tienen la misma base: el naturalismo que atribuye a Cervantes. Quiere hacer de él uno de aquellos herejes modernos a que alude Lucas de Tuy que escribía: "Con apariencia de filósofos quieren pervertir las Sagradas Escrituras... Atribuyen a la naturaleza todo lo que Dios realiza cada día con orden maravilloso... dicen que confirió a la naturaleza el poder de hacer todo" ?

Este fatalismo de Castro procede del estoicismo. Pero creo que el posible "senequismo" está dulcificado en Cervantes por la moral cristiana. Si se alude en algunos pasajes a Séneca es solamente en aquello que coincide con la doctrina moral bíblica o cristiana.

El concepto de "mayordomo de Dios" sobre la naturaleza, parece una doctrina del Renacimiento, afirma Castro. La Inquisición no la prohibió por ser lugar común literario, asiente Peña. Pero insisto en que la idea es totalmente bíblica: Dios actúa por la naturaleza, le manda y ordena:

«El que cubre de nubes los cielos,

el que lluvia a la tierra prepara,

el que hace germinar en los montes la hierba,

y las plantas para usos del hombre,

el que dispensa a los ganados su sustento...

como lana distribuye la nieve,

esparce la escarcha cual ceniza.

Arroja su hielo como migas de pan,

a su frío ¿quién puede resistir?» (Ps. 147,8.9.16.17. Ver también el bellísimo canto de Job sobre la creación, cap. 38).

Solamente Castro reconoce la postura de Cervantes contra el fatalismo de origen islámico, y a favor de la Providencia en el siguiente texto:

"La suerte fatal que, según la opinión de los que no tienen lumbre de fe, todo lo guían $(\mathbf{I}, 23)$.

1 El pensamiento de Cervantes, ed. de 1925, p. 337.

2 Américo Castro y su visión de España y de Cervantes. Madrid, Gredos, 1975, pp. 201-202, nota 56. Ver también GREEN, España y la tradición occidental Madrid, Gredos, 1969, vol. II, pp. 90 y ss. 
No se llega a comprender cómo el señor Castro no vio la misma Providencia en los otros lugares tan esclarecedores como hemos citado.

John Allen quien, por un lado identifica providencia con lo que se ha llamado "ironía cómica general", ve la Providencia de Dios en muchos pasajes del Quijote sin que se cite la palabra. Las novelitas intercaladas en la primera parte de la obra, reiteran la confirmación de la operación de la Providencia de Dios (Amores de Cardenio y Luscinda, de Fernando y Dorotea). En el encuentro con el bandolero Roque Guinart, don Quijote melancólico es advertido por el ladrón:

«Podía ser que en estos tropiezos vuestra suerte torcida se enderezase; que el cielo, por extraños y nunca vistos rodeos, de los hombres no imaginados, suele levantar los caídos y enriquecer los pobres" (II,60).

Así concluye allen sobre la actividad providente de Dios:

«El mundo del Quijote es un mundo regido de la Providencia divina. Las muchachas fieles y perseverantes se casan con sus galanes (Luscinda, Dorotea), las caprichosas y antojadizas salen frustradas (Altisidora). Hasta a un caballero joven y arrogante, acostumbrado a satisfacer sus deseos impunemente, se le puede encaminar por la senda de la razón y la virtud (Don Fernando). La cobardía y la malicia cuestan (Cardenio, Maritornes). El amor sincero triunfa (Basilio y Quiteria, Clara y Luis, Zoraida y el cautivo). ¿Sería don Quijote la única excepción dentro de este complejo de premios y castigos, la única víctima de una paradójica ironía cómica en un universo de benevolencia y justicia providencial? ${ }^{3}$.

Bien es verdad el juicio de Allen, pero aunque don Quijote sea la víctima y el apaleado, es él también quien más afirma la realidad de la Providencia divina, en los textos que hemos citado.

No siempre son ellos los creyentes en este atributo divino (Sancho o don Quijote). El mismo Cardenio se dirige al cura y al barbero:

«Bien veo yo, señores, quienquiera que seáis, que el cielo, que tiene cuidado de socorrer a los buenos, y aun a los malos muchas veces..." $(\mathbf{1}, 27)$.

A la expresión de Sancho de que "Dios sabe lo mejor y lo que está bien a cada uno» (II,55), doña Rodríguez tercia: "Dios nos echó en el mundo, Él sabe para qué y a su misericordia me atengon (II,40).

En La Gran Sultana, habla Madrigal sobre los elefantes a los que está educando en varias lenguas:

3 "La Providencia divina en el Quijote, en Cervantes, su obra y su mundo (Actas del I Congr. Intern. sobre Cervantes). Dirección de M. Criado de Val. Madrid, Edi 6, 1981, p. 228. 
«En todas [las lenguas] saldrá perito,

si le place al infinito sustentador de los buenos y aun de los malos, pues hace que a todos alumbre el sol» (Jorn. II).

Así, pues, Cervantes cita y parafrasea la Biblia en una de sus doctrinas transcendentales, donde no se hace una mera alusión esporádica o irónica, sino un cuerpo de ideas que proceden de su convencimiento personal de que Dios cuida al hombre en su azarosa vida.

Me parece que Cervantes no tuvo necesidad de acudir a Valla, El Cusano, Giordano Bruno, Campanella, etc., para tomar las ideas naturalistas de los humanistas italianos, como afirma Castro. Es cierto que estas ideas circulaban por España y buscaban la edad dorada, la perfección natural y el "Beatus ille»; la novela pastoril sería el resultado de estos anhelos.

Pero, Cervantes no es naturalista. El concepto laico de Américo Castro sobre "naturaleza", que le atribuye al Manco de Lepanto, le va a servir para interpretar ciertos hechos religiosos diseminados en las obras cervantinas. De aquí nace también la tesis de su "hipocresía", hasta ahora no demostrada contundentemente, y mucho menos en el tema de la Providencia divina.

La Providencia de Dios se cuida de los buenos y de los malos. Su infinita misericordia hace salir el sol para los justos e injustos. Pero esto no impide que Dios castigue las culpas de los malvados. A primera vista parece una contradicción del cuidado que Dios mantiene con toda la creación, incluso con las personas que no cumplen.

Así, pues, Cervantes se une a la tradición literaria española, a la Patrística y a la Biblia, al reconocer que el pecado es la causa de nuestros males. Los acontecimientos adversos, las derrotas en las batallas y otras desventuras, se deben a los pecados de la cristiandad, y por ello hay que satisfacer con alguna pena o penitencia, no sólo voluntaria y personal, sino con las desgracias y desventuras que nos acarrea la vida.

Esta ideología representa una especie de Providencia, con la que "quiere y permite Dios que tengamos siempre verdugos que nos castiguen" $(\mathrm{I}, 39)$.

No es el reverso de la misericordia, sino una nueva clase del atributo divino, que nos sirve de medicina curativa, más que punitiva. No obstante, los escritores exageran este castigo por los pecados, en cuya línea se coloca también Cervantes.

Así dice Sancho a su amo:

«Paréceme, señor mío, que todas estas desventuras que estos días nos han sucedido, sin duda alguna han sido pena del pecado cometido por vuestra merced contra la orden de caballería, no habiendo cumplido el 
juramento que hizo de no comer pan a manteles ni con la reina folgar" $(I, 19)$.

A don Quijote, ensangrentado y escarmentado en la aventura de los yangüeses, le viene a la mente el origen sobrenatural de las aflicciones humanas:

*...y así, creo que, en pena de haber pasado las leyes de la caballería, ha permitido el Dios de las batallas que se me diese este castigon $(I, 15)$.

Américo Castro comenta esta clase de infortunios después de haber cometido un pecado. Para él esta corriente se deriva de pomponazzi "para quien las culpas y las penas son fatales, y las virtudes y los vicios llevan en sí mismos sus sanciones; se halla [Cervantes], en el fondo, en la misma postura moral de Telesio o Campanella» 4 .

No estamos de acuerdo con el señor Castro, como demostraré más abajo. Cervantes persiste en la idea, a propósito de los sucesos y batallas contra los turcos. En el capítulo 39 de la I Parte repite este pesar:

«Por culpa de nuestros pecados se perdió La Goleta» $(I, 39)$.

De nuevo especifica las maldades que se cometían dentro de La Goleta:

«Pero a muchos les pareció, y así me pareció a mí, que fue particular gracia y merced que el cielo hizo a España que se asolase aquella oficina y capa de maldades, y aquella gomia, esponja y polilla de la infinidad de dineros que allí sin provecho se gastaban» $(I, 39)$.

El cautivo cuenta en este y otros textos la historia de las batallas contra el Turco, con rasgos históricos (no es otro que el mismo Cervantes que participó en esta guerra). Allí se perdió La Goleta, no por pereza de los soldados, sino por sus pecados. Alli se perdió Navarino y murieron valientes soldados españoles:

«Pero el cielo lo ordenó de otra manera, no por culpa y descuido del general que a los nuestros regía, sino por los pecados de la cristiandad, y porque quiere y permite Dios que tengamos siempre verdugos que nos castiguen" $(\mathrm{I}, 39)$.

En la Bula de Paulo III, que convocaba el Concilio de Trento, se comentan los mismos sucesos. Las pérdidas y derrotas de los cristianos, se deben a sus pecados. Quizás de aquí recibió influjos nuestro escritor. Así escribe el Papa en su Bula:

4 El pensamiento de Cervantes. Buenos Aires, 1925 (Anejo VI de RFE), pp. 255 256. Hay otra edición por Julio Rodríguez Puértolas, Barcelona, Noguer, 1972. 
"Por los yerros y culpas de todos nosotros, ya al descargar la ira divina sobre nuestros pecados, se perdió la isla de Rodas... Juzgaba [el turco] que los odios y disensiones que fomentaban los cristianos entre sí, era la ocasión más oportuna para ejecutar felizmente sus designios" s.

No sólo las palabras de Paulo III, sino la Decretal sobre la Penitencia, mantiene la misma idea:

«Enseña además el sagrado concilio que es tanta la liberalidad de la divina beneficiencia, que no sólo podemos satisfacer a Dios Padre... con las penitencias que voluntariamente emprendemos... sino también, lo que es grandísima prueba de su amor, con los castigos temporales que Dios nos envia, y padecemos con resignación" (Ses. XIV, cap. IX; Ayala, pp. 167-168).

Tanto Cervantes como el Concilio, no hacen más que seguir la tradición de la literatura española y de los Santos Padres. Para Gonzalo de Berceo, los hombres que persiguieron a Jesús acabaron mal (Loores, c. 119). Herodes se mató con su propia mano tras larga y dolorosa enfermedad (Loo. 39 y 120), Judas tuvo un final desastroso (Loo. 120). Herodes "el segundo" (Agripa) fue herido de muerte por un ángel (Loo. 121). Pilato se suicidó porque se volvió loco (Loo. 121).

En la Vida de Santo Domingo Berceo escribe:

"Todo esto abiene por nuestros pecados, que somos pecadores e non nos enmendamos" (c. 203).

"Si non lo tollieren nuestros graves pecados,

seredes de reliquias ricos e abondados" (c. 283. Ver lo mismo en coplas $366,426-431,449,557,560$, etc.).

En los Milagros de Nuestra Señora señala:

«Murió por sus pecados por fiera pasión nin priso Corpus Domini, nin fizo confesión" (c. 163).

Un convento fue destruido por un rayo a causa de los pecados de los monjes (c. 16. Ver además las coplas 275, 411, 440, 564, 633, etc.).

Para el autor de El Libro de Alexandre, los infortunios, las derrotas que sufría Alejandro Magno y las desgracias personales, se deben a los pecados de los protagonistas. Cuando Alejandro pregunta por una multitud de extranjeros que vivían en Babilonia, se le contesta:

"Judios son que yacen en su captividat, gentes a quien Dios fizo mucha de piedat; mas ellos non sopieron guardarle lealtat,

5 I. LÓPez de Ayala, El Sacrosanto y Ecuménico Concilio de Trento. Nueva edición. París, Librería Rosa y Buret, 1857, p. 2. 
por ende son caidos en tanta mesquindat" (c. 2104)

(Véanse las c. de este libro: 892, 1204, 1443, 1449, etc.).

El mismo pensamiento expone el Libro de Apolonio (coplas 130, $248,256,379,441,479,491,534,538$, etc.). De la misma manera escribe el Poema de Fernán González (coplas 90-102, 122, 125, 255, 256, etc.). Pedro López de Ayala sigue a Berceo en los castigos a los personajes bíblicos malvados (coplas 38, 46, 59-61, 212, 418, 1734, 1616, 1920, 2014, 2074-2075, etc.). Así concluye el Canciller:

"esto sería muy grave y muy sin razón

que el malo non padesca segunt su merescer" (c. 1490).

Del mismo modo se expone la causalidad del pecado en $L a$ picara Justina:

«...permite Dios que el pecador no sólo no consiga los gustos que pretende con sus quimeras, pero ordena y quiere que ellas sean instrumentos de sus penas y verdugos de sus personas" ${ }^{6}$.

Avanzando hacia atrás, el origen de toda esta ideología parte de la Biblia misma. De ella bebieron los Santos Padres y de éstos los poetas del s. XIII-XIV, los espiritualistas, el Concilio de Trento y Cervantes. No proviene, pues de Pomponazzi como opinaba Castro.

Los pofetas, principalmente Isaías, Jeremías, Ezequiel, Oseas y Amós, anuncian constantemente la venida del Reino Norte (Babilonia), que arrasará a Israel por el incumplimiento de la Alianza que Dios selló con el pueblo en el Sinaí. El mal afectará a todo el pueblo, a los sacerdotes, profetas y reyes. El Templo será quemado y la ciudad arrasada. El pueblo será deportado. Todas estas desgracias se deben al pecado de los distintos estamentos sociales y religiosos, como lo expresaba el Libro de Alexandre.

Los judíos del N.T. estaban convencidos que las enfermedades se debían al pecado del enfermo:

"Maestro, ¿quién pecó, éste o su padre para que naciera ciego?" (Jn. 9,1-2).

Esta concepción de que Dios castiga a los hijos por los pecados de los padres, se debe al Libro del Éxodo:

"Dios castiga la iniquidad de los padres en sus hijos» (Éx. 20,5).

Pero el Deuteronomio, que lo admite, por un lado $(5,9)$, lo rechaza más tarde:

6 Ver mi tesis doctoral El uso de los personajes biblicos en los poetas castellanos (s. XII-XIV). Univ. de La Laguna, 1987, pp. 62-67. 
"No morirán los padres por culpa de los hijos, ni los hijos por culpa de los padres. Cada cual morirá por su propio pecadon (Dt. 24,16).

Muchos profetas se adhieren a esta opinión, y sólo admiten la retribución individual, que reafirma la libertad del hombre en sus acciones (Jer. 31,29-30; Ez. 14,12-20; 18,10-20; Ecclo. 15,11-20, etc.).

Jesús destruye el equívoco de los apóstoles:

"Ni éste pecó ni su padre; es para que se manifieste la obra de Dios» (Jn. 9,3).

El Nuevo Testamento da un paso mayor en la concepción vieja. Ni el padre ni el hijo pecaron. El pecado no es causa de males. Pero a pesar de ello, el mismo Jesús la admite claramente cuando sana al enfermo de la piscina de Siloé:

"Mira estás curado; no peques más para que no te suceda algo peor" (Jn. 5,14 y 8,11 ).

Quizás lo admita el Señor, para ponerse a la altura del enfermo, que así lo creía, según toda la corriente de la exégesis rabínica. Los comentarios bíblicos evitan la unión de pecado-enfermedad. Lo mismo opina Laín Entralgo en un documentado artículo, sosteniendo que el cristianismo vuelve al concepto de enfermedad (hacia el s. III), conforme a la teoría de Galeno; es decir, que la enfermedad es obra de la naturaleza, y no tiene relación alguna con premios o castigos?

Pero la Biblia une a la naturaleza con la retribución. El Libro de la Sabiduría lo expone, al analizar las plagas de Egipto:

«El universo combate en favor de los justos» $(16,17)$.

"La creación se embravece para castigar a los inicuos" $(16,24)$.

Tampoco creo que se restableciera el concepto de enfermedadpecado hacia el siglo III, pues esta idea traspasa los umbrales del N.T. y llega a la Didascalia Apostolorum, Cipriano de Cartago ( $\mathrm{De}$ lapsis"), a Gregorio de Nisa y otros muchos Santos Padres y Escritores Eclesiásticos hasta el s. XII ${ }^{8}$. Los poetas castellanos, anteriores al s. XV la afirman con fuerza, como hemos visto, desconociendo la postura tajante de Jesús. A ella se une también Cervantes.

Es más, el corto reinado de los reyes godos Favila y Fabia se debe a un castigo de Dios por sus pecados. A propósito de ello, rvantes cita un romance sobre el desgraciado desenlace de Favila:

\footnotetext{
7 "La obra de Freud y el cristianismo primitivo", en Rev. de la Univ. de Madrid, I, 1952, pp. 494 y 496.

8 J. JANINI, «La penitencia medieval desde la Didascalia hasta Gregorio de Nisan, en Rev. Esp. de Teología, VII, 1947, pp. 337-362.
} 
«De los osos seas comido, como Favila el nombradon (II,34).

Don Quijote apostilla que se trata de un rey godo, y que el hecho ocurrió cuando estaba cazando. Esta tradición la había recogido antes el Poema de Fernán González, de la que deduce una conclusión moral:

"Rreynó su fijo Favila que fue muy mal varón, quiso Dios que mandase poco en la rregión" (copla 122).

"Rreignó su fijo Fabya que fue malo provado, quiso Dios que vysquiese poco en el rreynado" (c. 125).

Esta ideología procede de una síntesis teológica de Los Libros de las Crónicas o Paralipómenos, que aprovechan los datos históricos de los Libros de los Reyes, para extraer consecuencias morales. Así los monarcas Yoyaquín Joaquín y Sedecías reinaron poco tiempo y les llegó la muerte temprana, porque hicieron el mal y no agradaron a Dios (II Cron. 36, 5.9.11.12).

La doctrina bíblica sobre el pecado como causa de nuestros infortunios y males, era tradicional en los autores ascéticos de su tiempo. El padre Alonso Rodríguez, coetáneo de Cervantes (15371616), escribía sobre el particular:

«Doctrina es común de los santos, que suele Dios enviar estos trabajos y castigos generales comúnmente por pecados cometidos" ?.

El Jesuita acude a la Escritura citando a Dan. 3,28 ss.; Judit, 5,5 ss.; Jn. 5,14; las opiniones de San Gregorio Magno, etc. Por los pecados de uno, además, castiga Dios a todo el pueblo. Así, por el pecado de David, Dios envió la peste al país (II Reg. 24,15); por el pecado de Acán, Dios castigó a los soldados (Josué 7, 4.5.11). Finalmente cita a Ex. 20,5, interpretando el castigo de los hijos por los pecados de los padres: el castigo es sólo "en cuanto a la pena», aunque cite a Ez. 18,20, que exime de este castigo general.

Cervantes, pues, tiene un alto concepto de la providencia divina, en sus dos vertientes: cuidado de todos los seres vivientes buenos o malos y permisión de los "verdugos que nos castiguen", como aviso y remedio curativo para los pecadores, en cuyo caso se puede considerar que se trata de una verdadera Providencia en favor de los malvados.

\section{CELSO BAÑeza RoMÁN}

9 Ejercicio de perfección y virtudes cristiana (Nueva ed. de 1606). Madrid, Apostolado de la Prensa, 1930, 1." pt. trat. VIII, cap. 23, pp. 744-752. 